\title{
Referential Intentions: A Response to Buchanan and Peet
}

\author{
Elmar Unnsteinsson \\ Postprint. Please cite published version: \\ Australasian fournal of Philosophy (2018) 96(3):610-615 \\ doi:10.1080/00048402.2018.1432666
}

\begin{abstract}
Buchanan (2014) argues for a Gricean solution to well-known counterexamples to direct reference theories of content. Peet (2016) develops a way to change the counterexample so that it seems to speak against Buchanan's own proposal. I argue that both theorists fail to notice a significant distinction between the kinds of cases at issue. Those appearing to count against direct reference theory must be described such that speakers have false beliefs about the identity of the object to which they intend to refer, beliefs that appear relevant to the determination of what constitutes communicative success. This suggests, further, that cases of this sort do not provide a basis for robust generalizations about singular reference.
\end{abstract}

\section{Introduction}

Buchanan (2014) argues that direct reference theorists can withstand a much discussed counterexample from Loar (1976) by appealing to independently plausible Gricean theories of communication. Here's Loar:

Suppose that Smith and Jones are unaware that the man being interviewed on television is someone they see on the train every morning and about whom, in that latter role, they have just been talking. Smith says 'He is a stockbroker', intending to refer to the man on television; Jones takes Smith to be referring to the man on the train. Now Jones, as it happens, has correctly identified Smith's referent, since the man on television is the man on the train; but he has failed to understand Smith's utterance. (1976: 357)

*(凶) elmar.geir@gmail.com

*Many thanks to two anonymous reviewers for this journal and to the audience at the 2017 Nova Scotia Meaning Workshop for great comments and many helpful suggestions. 
It seems like Jones grasps the Russellian proposition intended but, still, fails to understand the utterance. Cases like this are widely thought to motivate Fregean views of propositions.

On Buchanan's view, however, DR theorists shouldn't admit defeat so easily. Certainly, recovery of the Russellian proposition intended is not sufficient for communication but, as Griceans would emphasize, speakers' communicative intentions always have more structure than this. Specifically, speakers intend their utterances to have features the hearers' recognition of which will help them to work out what is meant. Schiffer (2016: 503) calls these features the 'inference base'-IB-features for short.

Thus, communication could appear to fail because the hearer doesn't recognize the IB-features intended, while still grasping the intended proposition, either by mere luck or, perhaps, by using IB-features other than those intended. Buchanan makes this possibility vivid with an example where, both knowing that their local theater is showing the cowboy movie 'Flat-top mountain,'

[Smith] draws a mountain (in clear view of Jones), intending to communicate thereby that he would like to go to see Flat-top Mountain. Jones, however, mistakes the drawing for one of a cowboy hat, and infers thereby that Smith would like to go to see Flat-top Mountain. (2014: 62).

Communication, strictly speaking, fails. Jones latched on to the intended proposition by luck rather than by design.

This is also, according to Buchanan, what happens in Loar's case. Smith intends Jones to infer what is meant on the basis of an IB-feature of his utterance of 'he,' namely, that it is 'common ground between [them] that there is a particular man, o, being interviewed on TV right in front of them' (2014: 67). But Jones doesn't infer Smith's meaning on the basis of this feature, not even in part. This fully explains, according to Buchanan, why communication fails. Peet (2016) disagrees. Suppose, again, that Smith says to Jones 'He is a stockbroker' intending to refer to the man on TV. But now, Jones realizes that Smith intends for him to use their mutual knowledge (there is a man on TV) to infer his referential intention. So, Jones recognizes the intended IB-feature. However, he wrongly assumes that Smith intends to draw his attention to how similar the man on TV is to the man whom they see on the train every morning. Jones infers that Smith is referring to the man on the train and not the man on TV. Peet concludes that 'Jones reached the correct interpretation by inference from the intended features of the utterance' (2016: 381). Communication still failed. 


\section{The Hidden Problem}

There is a theoretically significant difference between Loar's example and Buchanan's, which seems to have gone unnoticed. Suppose Jones has just inferred, on the basis of seeing Smith's drawing, that Smith wants to see Flat-top Mountain. Suppose also that Jones is wearing a bowler hat. He takes it off and says, 'Can you draw this one, too?' Smith immediately realizes that Jones thought that he was trying to draw a cowboy hat, and that he had inferred his referential intention, not unreasonably, on that basis. What would Smith's reaction be? Two options readily suggest themselves. Either he is indifferent about the misunderstanding and, pretending Jones had correctly identified what he was trying to draw, proceeds to draw a bowler hat next to the cowboy hat/flat-top mountain. Otherwise, Smith might be annoyed by the misunderstanding and might make clear to Jones that he drew a mountain, not a hat (he could compare the drawing to the movie poster, for instance). Let's call cases like this 'permissive.'

Compare this to what would happen in Loar's example. As before, Smith says, 'He is a stockbroker', intending to refer to the man on TV. Jones takes Smith to be referring to the man on the train. Smith suddenly realizes that Jones hasn't been paying attention to the TV and must have taken him to be referring to the man on the train, about whom they had just been talking. Now, what prediction would we then make about Smith's reaction? Most significantly, complete indifference would be quite irrational or, at least, communicatively uncooperative. From Smith's perspective, Jones has completely misunderstood, for he (Smith) takes there to be two men-let us call them 'TV-man' and 'Train-man'-and he definitely intends to refer to one and definitely intends not to refer to the other. And so Smith would probably correct the misunderstanding by insisting to Jones that he wasn't talking about Train-man. This seems to apply, also, to Peet's variation. Let's call cases like this 'restrictive.'

These differences in intuitive predictions point to a difference between the mental states of speakers in permissive and in restrictive situations, at least for these examples. In the restrictive cases, speakers have a false belief about the identity of the object to which they intend to refer. In Loar's example this is the false belief that TV-man $\neq$ Train-man. True, this is not how Smith would represent the belief to himself and it's not even necessary that he consciously entertain any particular belief with some such content. Either way, it's clear that he has some belief or collection of beliefs, on the occasion of utterance, which is conveniently labeled, from a third-person point of view, as the belief that TV-man $\neq$ Train-man. In Buchanan's example no such false belief is in play. We are not asked to suppose that Smith believes falsely that Flat-top mountain is not identical to some 'other' movie.

Notice, further, that transforming the restrictive case into a permissive one requires nothing over and above correcting the speaker's false belief. So, if Smith 
knows that TV-man = Train-man, but still utters 'He is a stockbroker' intending to refer to the man on TV and, further, that Jones use the same IB-feature as before to infer his referential intention, the example immediately becomes permissive. If Smith realizes that Jones took him to be referring to Train-man, he might not care at all, since he knows that TV-man = Train-man. If the IB-features, or the fact that Jones is confused, happen to matter to Smith for some reason, he may choose to correct Jones about those aspects of the situation. Whether he does so depends on further features of his communicative intention. For example, Smith might say that the man is a stockbroker because of how he dresses on TV, assuming that this was not common knowledge among Jones and himself. In that case, the IB-feature may matter. Alternatively, if seeing the man on TV merely prompts Smith's thought that he's a stockbroker, forgetting momentarily that they've been talking about him already, as Train-man, he might (rationally) not care at all that Jones failed to grasp the IB-feature. He used some other IB-feature, one that Smith merely forgot was readily available.

More precisely, define permissiveness for singular propositions as when speaker $S$ performs the act $U$ of uttering something, intending thereby (i) to communicate an $o$-dependent proposition $p$ to hearer $H$ and (ii) that $U$ have IB-features $f$ on the basis of which $H$ can infer (i), but (iii) if $H$ uses some other IB-feature $f^{\prime}$ of $U, S$ can be indifferent and still cooperative. As theorists, we are free to insist that communication fails, strictly speaking, when $H$ uses $f^{\prime}$; the point is that this need not matter for practical purposes. Restrictiveness is defined in terms of cases where the realization that $H$ used $f^{\prime}$ would compel cooperative speakers to judge that $H$ had misunderstood the utterance. So defined, these two notions are messy, for speakers can take almost anything as reason to believe their interlocutor has misunderstood. There is, however, a strong connection between restrictiveness and identity confusion. If there is an $x$ such that $S$ happens to have a contextually relevant false belief of the form $x \neq o$ and $S$ realizes that, relative to some IB-feature of $U, H$ took $S$ to be referring to $x$ and not to $o$ in communicating $p, S$ is compelled if cooperative to judge that $H$ misunderstood.

It seems safe to say that Buchanan has shown that DR theorists can appeal to the independently motivated idea of IB-features to explain what communicative success and failure come to in the permissive cases. Strictly speaking, Buchanan only offers necessary conditions on communicative success, of help to DR theorists, without asserting their sufficiency. Thus, Peet's counterexample ultimately fails, for it targets the sufficiency of the conditions. Reading between the lines, however, Buchanan seems to aim for something like this: $H$ understands $S$ 's utterance iff $H$ infers $S$ 's intention-part of which is the referential intention-on the basis of the utterance in a permissible or intended way (see, e.g., Bach \& Harnish 1979, ch. 5). Call this rough idea, also committed to direct reference, the 'DR/Gricean theory.'

Now, the problem that neither author notices is that Buchanan's strategy doesn't carry over, without change, to restrictive cases where the speaker is confused. This 
is the hidden lesson of Peet's counterexample. It shows that restrictive Loar-type examples can always, in principle, be modified such that the hearer's recognition of IB-features and the Russellian proposition appear to be jointly insufficient for successful communication. By my reckoning, none of Buchanan's examples, apart from Flat-top Mountain, is specific enough to determine whether it is restrictive or permissive. Take 'Case Two':

Smith and Jones are sitting on a park bench, as Smith is reading a story regarding the non-music-related business ventures of [Bob] Dylan in The Wall Street Journal. The centre spread has a large picture of Dylan to which Smith nonchalantly gestures and utters ['That rock star is a stockbroker']. Jones, however, takes Smith to be intending to refer to a certain man sitting directly across from them in the park-one who happens to be Dylan. Even if, as a result of Smith's utterance, Jones correctly identifies to whom Smith is referring with 'he', and fully understands what Smith is predicating of him, intuitively, he has not understood Smith's utterance. (2014: 58)

Either Smith knows (i) that WSJ-man = Park-man or he falsely believes (ii) that WSJ-man $\neq$ Park-man. It's also possible that (iii) Smith hasn't noticed the man in the park who happens to be Dylan and, so, can't be assigned either belief (apart from dispositionally, perhaps). Anyway, only the restrictive reading could be a potential problem for the DR/Gricean theory. If I point to a picture of Dylan, knowing that Dylan is also sitting somewhere in plain view, and say to you that that rock star is a stockbroker, it would be very strange of me to insist that you misunderstood what I said, since you took me to be referring to the man in plain view. I was referring to him as well. If I believe (ii) or, not having noticed the man yet, start believing (ii) when I realize what IB-feature you used, I will take it that you misunderstood, while a fully developed DR/Gricean theory might predict success. In case (i) is my mere dispositional belief, I may think, 'What a lucky coincidence, he's sitting right there!' I don't care which IB-feature you use, even if I intend to design my utterance so as to have at least one useful such feature. So, even that case is permissive.

The case remains a problem, when restrictive in virtue of Smith believing (ii), because communication intuitively fails whenever Jones takes some IB-feature to indicate the man whom Smith believes, or is disposed to believe, is Park-man (such that Park-man $\neq$ WSJ-man). The DR/Gricean theorists could, at this point, try to add further conditions to deal with this kind of case, but there is no obvious way to do so. I want to suggest a more radical response on their behalf. This cannot be developed in detail here for reasons of space (but see Unnsteinsson 2016, 2017, forthcoming). We have now a fairly precise description of the facts giving rise to recalcitrant cases-namely, that the speaker must have relevant false beliefs about the identity of the object seemingly referred to, such that our intuitive 
judgments of communicative success get thrown off the tracks laid down by a plausible theory. The idea is that lacking such false beliefs at the time of utterance can be a condition on the proper functioning of the underlying mechanism of singular communication. In trying to refer to an object $o$, one underlying goal or assumption of speakers is that there is no contextually salient $x$ such that they believe falsely that $x=o$. One legitimate idealization, it seems, is to refuse to assign a unique referent to utterances for which the assumption is false, allowing however that some assignments may be good enough for mere practical purposes. Unconfused speakers can still be assumed to refer. Loar-type cases are special, in that the speaker is actively considering what she takes to be two objects, but is in fact one, and trying to switch from talking about one, to talking about the other. This creates illusion-like scenarios for both speaker and hearer.

The illusion comes from considering the potential implications for the notion of communicative success. Loar assumes, as we have done, that Smith and Jones are both confused about the identity of the stockbroker. What if Jones, the hearer, is not confused at all but knows about Smith's confusion? What constitutes Jones' grasping the proposition intended by Smith in such a case? This is far from clear. He could assign the impossible object $o$ such that $o=$ TV-man $\neq$ Train-man. Or he could assign the actual man he knows to be both Train-man and TV-man. Neither assignment seems ideal. When both are confused, Loar asserts that Smith has correctly identified Smith's referent but, of course, he as identified an impossible object, even if he isn't consciously aware of this. One upshot should be, I suggest, that confusion of this kind gives rise to examples where apparently intuitive judgments about communicative success do not provide robust grounds from which to generalize. More positively, the DR/Gricean theorist can argue that it is in the nature of the speech act of singular reference that having specific false beliefs about identity can make it impossible for a speaker to perform the act properly. Improper performances can be explained by describing the particular mental state of confusion and the complex structure of goals an act of reference is supposed to achieve, one part of which is to refer to something about which one is not relevantly confused (Unnsteinsson 2016, forthcoming).

The argument from Loar-type cases to Fregeanism about propositions seems, more and more, structurally analogous to the idea that the ever-present possibility of illusion or hallucination is sufficient ground for thinking that one only ever perceives objects through intermediary representations, never directly. Perhaps perception is indirect, but many theorists think that this kind of argument is inconclusive. There are too many strategies of idealization or relativization that first need to be considered. Similarly, we have Loar-type cases because speakers may harbor false beliefs-illusions-about the identity of an object at the time of utterance. Some conclude from this that reference is not direct, positing Fregean senses. It seems, however, that if the features giving rise to these cases are well understood and result, arguably, from specific failures of our belief-forming mechanism, they 
can be isolated and treated as special cases. Our aim is, in the first instance, to explain how the communication of singular reference works when all goes according to plan-namely, when the mechanism that we want to understand functions properly. On this picture, communication fails in the Loar case even more radically than he supposed, and this could be accommodated by allowing the DR/Gricean theorist a certain leeway for idealization in pursuit of explanation.

\section{Bibliography}

Bach, K. \& Harnish, R., 1979. Linguistic communication and speech acts. MIT Press. Buchanan, R., 2014. "Reference, Understanding, and Communication." Australasian fournal of Philosophy, 92(1):55-70.

Loar, B., 1976. "The semantics of singular terms.” Philosophical Studies, 30(6):353377.

Peet, A., 2016. "Referential Intentions and Communicative Luck." Australasian fournal of Philosophy, 95(2):379-384.

Schiffer, S., 2016. "Gricean semantics and reference." G. Ostertag (ed.), Meanings and other things:, OUP, pp. 493-527.

Unnsteinsson, E., 2016. "Confusion is Corruptive Belief in False Identity." Canadian fournal of Philosophy, 46(2):204-227.

---, 2017. "A Gricean Theory of Malaprops." Mind and Language, 32(4):446-462.

- - , forthcoming. "The Edenic Theory of Reference." Inquiry. 